\title{
Capital Markets Union: The Key to Restoring the Economic Growth and the Real Convergence in the Eurozone
}

\author{
Antonin Rusek \\ Dept. of Economics, Susquehanna University \\ Selinsgrove, PA 17870, USA
}

\begin{abstract}
In the next decade or so the EU will face complete set of challenges. To confront successfully these challenges, the restoration of growth is the imperative. That means to restore the competitiveness especially on the Mediterranean littoral and hopefully the real convergence. Renewal of the North to South capital flows is the sine qua non of this development. The main tool in this endeavor is the emerging capital markets union, which will facilitate the increased activities of the venture capital - the main tool to create the new economy of innovation and creativity. But to be successful the capital markets union has to be complemented by reforms of labor markets, business creation environment and taxation. New approaches like special "economic innovation and growth" zones may be necessary. To fully implement the necessary structural reforms the cooperation of the private and public sector on both the EU and national levels is necessary.
\end{abstract}

Key Words: capital flows, capital markets union, venture capital

\section{INTRODUCTION}

The mixture of the recent EU policies - mainly the "fiscal compact" and the OMT approach by the ECB - restored the nominal stability for the Eurozone and therefore preserved the common currency. However, the same steps resulted in a widening gap between the Northern tier and the Mediterranean countries. To address this issue - which is potentially a mortal threat to the Eurozone in its present configuration - the three policy options are available: A restoration of a real convergence, the Eurozone's restructuring or a "muddling through". The first two require radical policy steps which in the present political and economic climate are commonly considered unlikely. That leaves a "muddling through" as the likeliest future approach. However, its inherent ad hoc nature breeds uncertainty, which, combined with a complacency stemming from the recent "successes" increases the possibility of destructive future dynamics.

In the next decade or so, the EU in general and the Eurozone in particular will face a complex set of challenges, both internally and externally. Most important of those will be a continuing rise of the emerging markets, with its asymmetric impact on the Eurozone member economies. (Chen at al., 2012) This will only exacerbate the increasing divergencies between the countries on the Mediterranean littoral and the countries North of Alps (referred to subsequently as south and north respectively). Finally, the demographic dynamics will exert influence over both the productivity and the fiscal positions.

To confront successfully these challenges, the restoration of growth is the imperative for the EU and the Eurozone's future. However, not any growth will do. The emerging markets challenge requires a growth based on the innovation and creativity (i.e. the increases in productivity), especially in the South. This type of growth improves competitiveness and 
should arrest and hopefully reverse the divergence tendencies. Moreover, its fiscal implications would help to address the looming demographic challenges - especially the rising expenditures on pensions and healthcare across the EU.

In this context, the three issues emerge. The first and the most important one is the fact that the economic activities associated with the innovation and creativity are inherently riskier than the expansion of the existing business endeavors. That creates a funding problem. European financial sector, dominated by banks, is unsuitable to finance the new innovative but overall highly risky business ventures, especially if those are undertaken by newly created firms.

The second issue relates to labor markets. The uncertainty associated with innovative ventures will be reflected in the need for flexible labor contracts, especially if these ventures are carried by the newly established firms. Moreover, the act of an establishment of a new enterprise faces complicated procedures in many, especially southern countries. Liberalization of the entry into professions and business activities in general is required to facilitate the desired economy of a growing productivity, i.e. the competitive and innovative economy.

Finally, the third issue is taxation. Increased uncertainty associated with the new enterprises constituting the new productive and innovative sector can be counteracted, at least partially, by designing a simplified (and perhaps even temporarily reduced) tax liability structure which would enhance the attractiveness of this sector for both the potential entrepreneurs and employees.

To address all three issues, actions on both the EU level and national levels are required.

Part II of this paper illustrates the co-movements of the economic per capita growth rates and the capital flows. Part III then argues that the restoration of the growth requires the restoration of capital flows - i.e. the raison d'etre for capital markets union. In this context the crucial role of the venture capital is emphasized. Part IV concludes.

\section{GROWTH AND CAPITAL FLOWS}

The dynamics of the per capita growth rates in the Eurozone is illustrated in Figure 1. For the analytical purposes, the Eurozone countries are divided into two groups. North (sometimes called core) countries compose of Germany, Austria, Netherlands, Finland, Luxembourg, Belgium and France. South (sometimes called periphery) is then constituted by Italy, Spain, Portugal, Greece and Ireland. Because of the paucity of reliable Euro denominated information - especially for the pre-crisis period - the data for the "new" Eurozone members (Slovakia, Slovenia, Malta, Greek Cyprus, Estonia, Latvia and Lithuania) are not included in the present discussion. 
FIGURE 1

GDP per Capita Growth
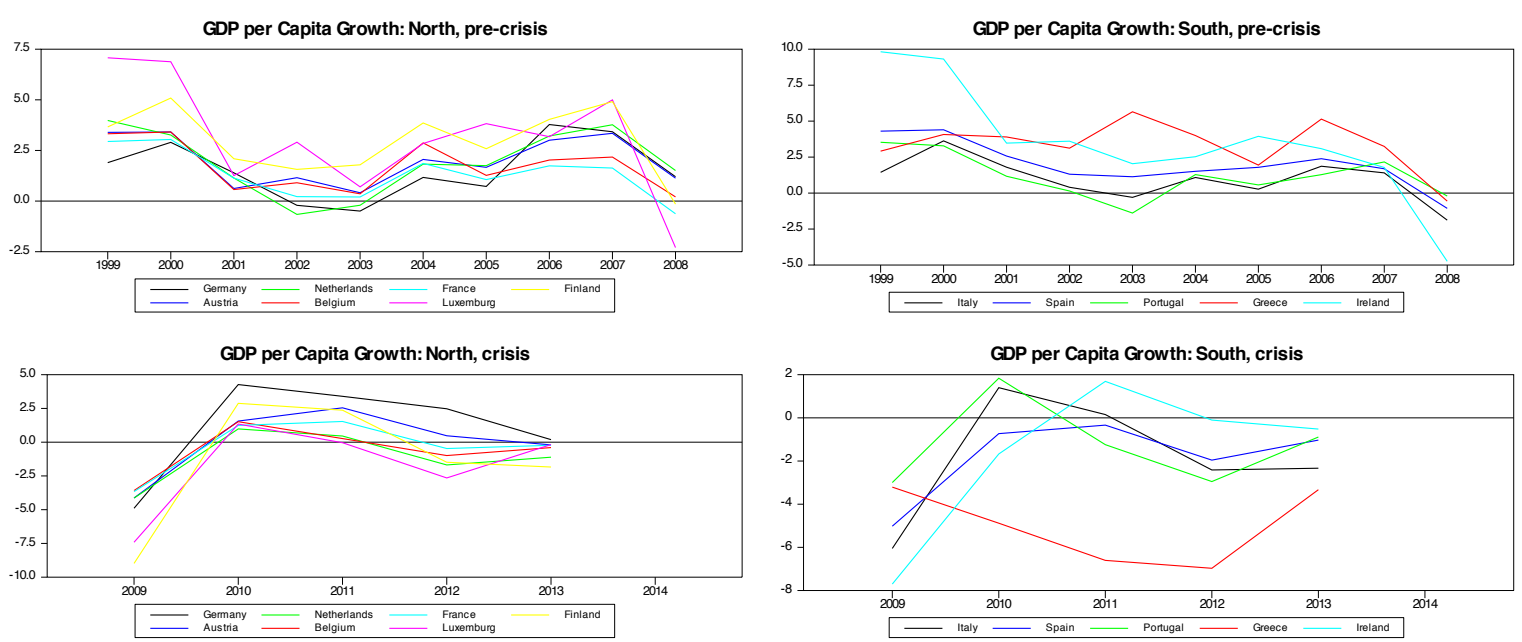

The above graphs indicate that whereas in the pre-crisis period (1999:Q1 - 2009:Q1) the growth of GDP per capita was predominantly positive and similar in both North and South, the situation changed subsequently. In the crisis period (2009:Q2 - 2014:Q2) the growth per capita in the North fluctuated around zero, but of stayed in a positive territory. In contrast, the southern "growth" became negative (with minor exemptions).

\section{FIGURE 2}

\section{Current Account To GDP Ratios}
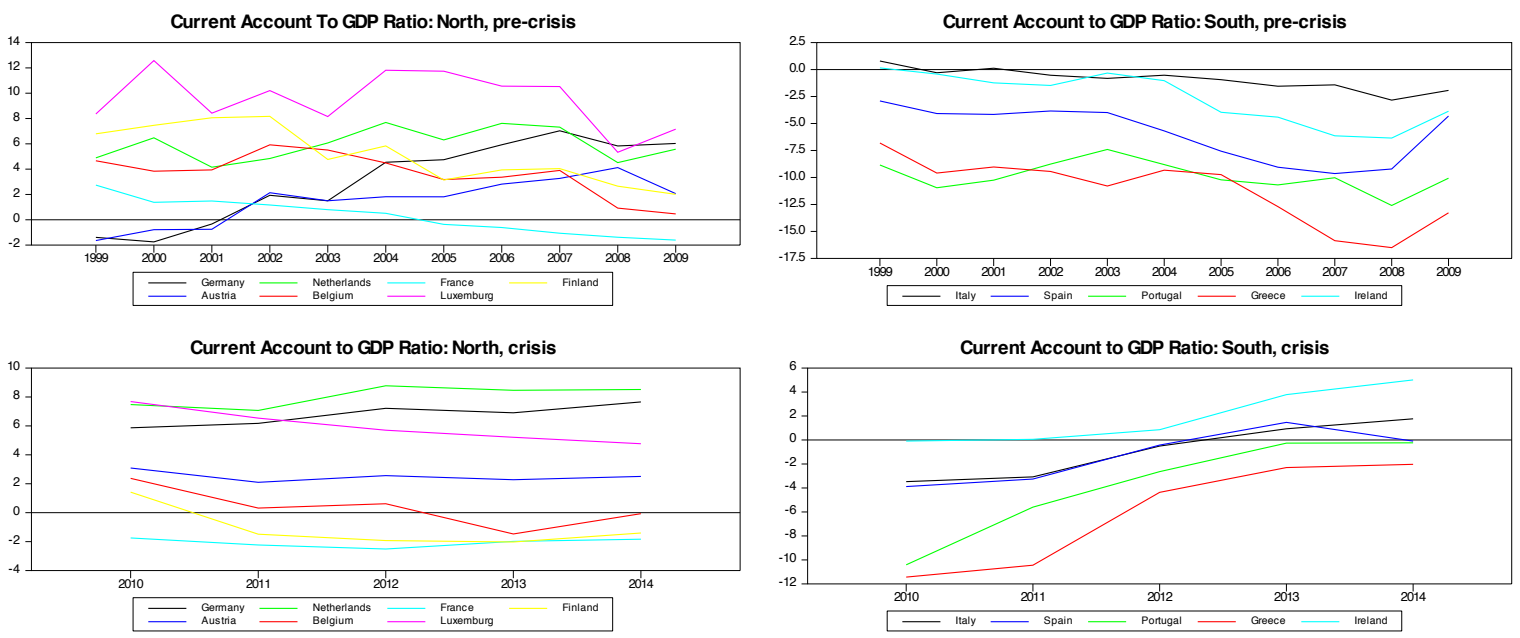

Figure 2 illustrates the dynamics of current accounts measured as the percentage of GDP. North (with some exceptions) generally preserves current account surpluses (positive current account to GDP ratios) in the both pre- and crisis periods. In contrast, the South displayed the persistent current accounts deficits in the pre-crisis period. And those deficits rather quickly evaporated during the crisis. Indeed, some southern countries show mild current account surpluses lately.

The visual comparison of Figures 1 and 2 suggests the relationship between the current account positions of the countries in the "South" group and theirs per capita GDP growth rates. It indicates that the "improvement" in the current account is correlated with the worsening of 
the economic performance (GDP per capita). That, indeed, makes economic sense. In the national accounts, the current account balance is the inverse of capital flows - i.e. the current account deficit indicates a capital inflow and vice versa. It follows that stabilization policies aimed at the reduction of domestic indebtness (both public and private) will result in reduction of demand for foreign debt and hence the reduction in capital inflow - i.e. the current account "improves".

But this mechanism reduces the availability of funds for spending (both public and private) for both the consumption and investments. This reduction in domestic demand then indeed reduces the economic growth, resulting in the increased unemployment. (For the detailed analysis of this phenomenon, see for example Giavazzi and Spaventa, 2011, Pisani-Ferry and Merler, 2012, Sinn, 2012)

Given the lower growth domestic savings in the South (compared to North - see Figure 3), capital inflow appears to be the indispensable element in the restoration of Southern investments and hence the all important recovery of the growth and competitiveness in the Mediterranean countries.

\section{FIGURE 3}

Gross Savings to GDP Ratio
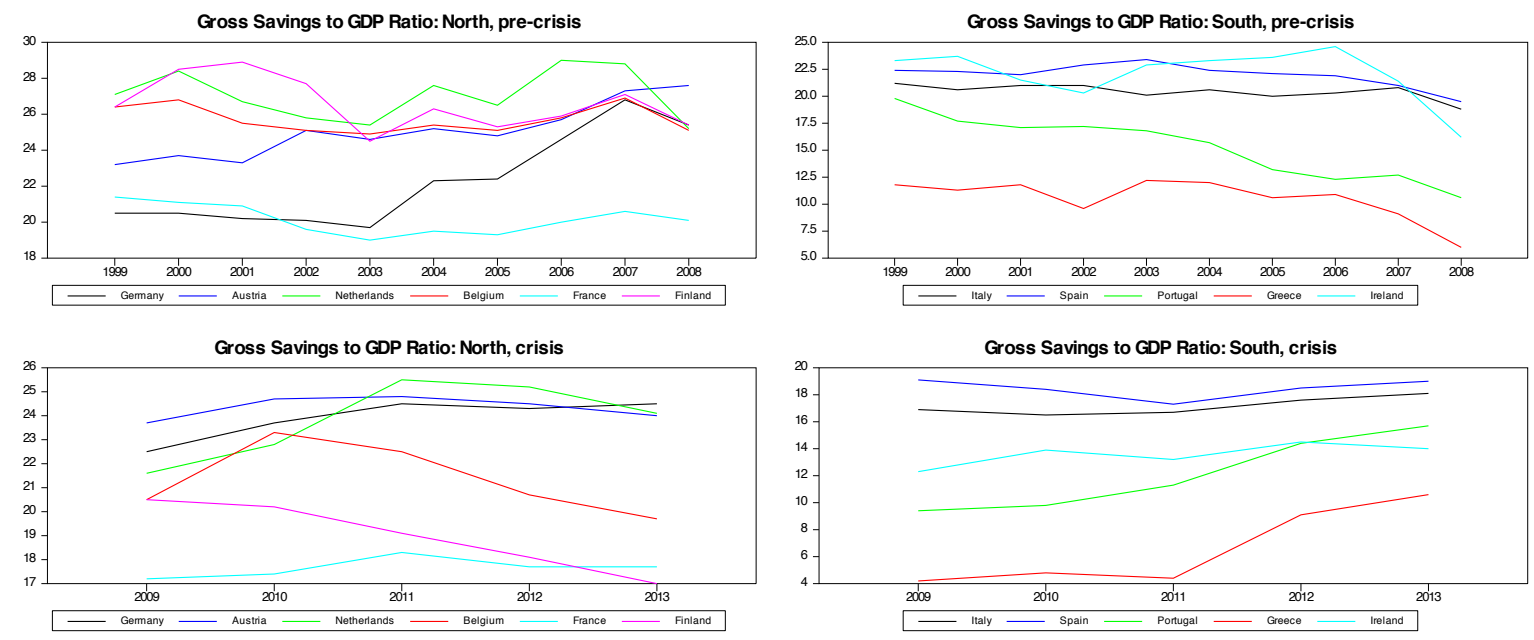

It follows that the restorations of the North - South capital flows are the key element for the EU and the Eurozone to regain its cohesion and dynamism. After all, the investments are the key to the increase in productivity, which in turn improves competitiveness and via a restored GDP growth restores the employment and hence the social stability.

\section{INVESTMENT, GROWTH AND CAPITAL MARKETS UNION}

The EU recognizes the key role of investments in shaping its future. The policy cornerstone of the new European commission (installed in 2014) is the 315 billion Euros investment plan, which the commission chairman J.C. Juncker calls "The New start for Europe" (Juncker, 2014). Perhaps more importantly, this "Juncker plan" is complemented by the new concept, the "Capital Markets Union" (Building a Capital Markets Union, 2015). Before its launch, this concept was extensively discussed (Hill, 2014, Veron, 2014) and, indeed, the discussion continues.

This analysis does not intend to join a growing field of technical discussions dealing with the technical elements of the Capital Markets Union (CMU) design and implementation, however important those might be. Instead, we concentrate on the irreplaceable role the CMU has in 
facilitating and enhancing the restoration of the investment concentrated capital flows. Indeed, the restoration of competitiveness via increasing productivity and the facilitation of the real convergence via full employment are among the CMU's most desired results.

Venture capital firms are the key vehicle for the creation and financing of the new innovative companies which in turn are the essence of the dynamic, productivity enhancing growth. The actual funds for the venture capital come from existing financial establishments, technically termed the "limited investors". (In the US these compose of the pension funds, university endowments, insurance companies, various investment and hedge funds etc.) To be able to allocate a relatively small part of their funds to the high risk but high expected return venture capital, the "limited investors" need the continuous ability to diversify and hedge the rest of their portfolios - i.e. to continually optimize the overall portfolio's risk-return configuration. This in turn requires the financial markets which are broad (in terms of the number of instruments available to trade), deep (in terms of the large number of instruments available with different risk-return characteristics) and liquid. The large and sophisticated US financial markets provide the environment in which both venture capital firms and "limited investors" strive.

The EU economy as a whole is greater than US, so theoretically it should be able to support the non-bank financial sector comparable to US. However, despite the advances of the last 15 years, European financial sector remains dominated by banks. Relatively small non-bank financial sector then does not provide a fertile environment for the venture capital (Building a Capital Markets Union, 2015).

Venture capital activity is the key for the creation of new firms which enhance productivity and competitiveness in the whole EU, but especially in the most negatively affected countries on the Mediterranean littoral. It would follow that the creation of a supportive environment for the venture capital activities should be one of the major goals for both the new European commission and the EU as a whole.

Indeed, the new leadership of the EU recognizes the importance of the non-banking financial sector on a trans-european scale (Juncker, 2014, Hill, 2014). On the analytical side, the importance of the integrated pan-european non-banking financial sector - called the "capital markets union" (CMU) is discussed by Veron (2014). What is needed is the accelerated path of the CMU establishment, with the emphasis on its role in facilitating the activities of the venture capital in the EU in general and in its Mediterranean member countries in particular.

The creation of the CMU as vehicle to restore the free flow of capital within the EU in general and the Eurozone in particular is the key to the political and economic stabilization of the Eurozone. It should help to restore the North to South capital flows and by facilitating the venture capital financing to help the South to promote the productivity growth and restore the competitiveness. And, indeed, the role of the European institutions is crucial in this undertaking.

However, the CMU alone is not enough to restore the Southern growth and, hopefully, the real convergence. The substantive structural changes in the Mediterranean littoral economies are needed to make these countries attractive location for the venture capital.

Indeed, structural reforms are at the heart of changes associated with Treaty on Stability, Coordination and Governance in the Economic and Monetary Union (TSCG), the key element of 
the European response to the recent fiscal and financial turmoil. However, the experience of the last half a decade indicates the difficulties, opposition and widespread resentment encountered when structural changes are implemented across the individual national economies.

To facilitate the environment which will be inviting to the venture capital endeavors - and hence providing for the start of the growth based on the innovation and productivity - perhaps a different approach should be attempted.

Individual countries should designate "economic growth and innovation areas" defined either territorially or perhaps as branches of economic activities. Within those areas, the structural reforms should be accelerated, with the aim to create a hospitable environment for the new businesses, preferably financed by a venture capital.

The creation of such areas will necessarily be country specific. Hence their establishment must be the common projects of the EU institutions and the relevant country political and economic partners. Note that the goal is to facilitate the increase in the economic activity (and hence the employment) by establishing the innovative and globally competitive economic sector in the countries on the Mediterranean littoral. When successful, this should arrest the North-South divergent tendencies within the EU and therefore to dynamically stabilize the common currency area.

The special nature of these areas and its success can be enhanced by an adjusted tax regime (the third issue mentioned above). Again, the details are specific to individual countries. Here it should be only mentioned the need for the preservation of a hardly won public finance stability and the motivational role of capital gains in the establishment and success of business endeavors financed by the venture capital.

The EU with cooperation of national government sets the rules governing this new reality. However, the actual activities are by and large private sector financed and operated. This by itself should contribute not only to the renewed employment dynamics, but to the stabilization of public finances as well.

\section{CONCLUSION}

Ideas expressed in this analysis seek ways how to restore the growth and global competitiveness in the EU and especially in the Mediterranean Eurozone members. They seek to overcome political and institutional obstacles and via an enhanced cooperation between the EU and the national governments to reinvigorate the process of the European integration and to arrest the growing divergence between the north and South. Not the least advantage is that no changes of the existing EU treaties and governance are required.

Finally, the ideas expressed above should not be perceived as the alternative for the European Fund for Strategic Investments (EFSI - commonly referred to as Juncker's Investment plan). Rather, both ideas should thought of as complimentary. EFSI seeks the increase in investments in the EU in general - especially in infrastructure. Ideas in this note seek the ways (and investments) aimed at the increases of productivity and global competitiveness via private sector activities especially in South. Our conjecture is that the EU - and especially the Eurozone - need both. 
Ruske, A. (2015). Capital Markets Union: The Key to Restoring the Economic Growth and the Real Convergence in the Eurozone. Archives of Business Research, 3(2), 172-178.

\section{References}

Building a Capital Markets Union (2015). Green Paper, European Comission, Brussels, February.

Chen, R., Milesi-Ferretti, G-M, and Tressel, T. (2012).” External imbalances in the Euro Area." IMF Working Paper, $12 / 236$.

Giavazzi, Francesco, Spaventa, Luigi (2011), "Why the current account may matter in a monetary union: lessons from the financial crisis in the euro area", CEPR Discussion Paper No. 8008

Hill, J. (2014) “Capital Markets Union: Finance Serving the Economy”. Speech at Finance and Growth Conference, Brusseles, Belgium, November 6th. (http://ec.europa.eu/rapid/press-releaseSPEECH-14-1460.en.htm)

Juncker, J.-C. (2014). “A New Start for Europe: My Agenda for Jobs, Growth, Fairness and Democratic Change.” Opening Statement at the European Parliament Plenary Session, July 15th. (http://ec.europa.eu/about/junckercommission/docs/pg.en.pdf)

Pisani-Ferry, Jean, Merler, Sylvia (2012). "Sudden Stops in the Euro Area”. Breughel Policy Contributions 2012/06, March

Sinn, Hans-Werner (Ed) (2012), "The European balance of payment crisis", CESifo Forum volume 13.

Veron, N. (2014). “Defining Europe’s Capital Markets Union”. Bruegel Policy Contribution, Issue 2014/12, November 